УДК 665.3+615:322

\title{
ХИМИЧЕСКИЙ СОСТАВ ЭФИРНОГО МАСЛА HYSSOPUS OFFICINALIS L., КУЛЬТИВИРУЕМОГО В АСТРАХАНСКОЙ ОБЛАСТИ
}

\author{
() А.В. Великородов", В.Б. Ковалев, Ф.Х. Курбанова, Е.В. Щепетова \\ Астраханский государственный университет, пл. Шаумяна, 1, Астрахань, \\ 414000 (Россия), e-mail: avelikorodov@mail.ru
}

Методом пародистилляции получены образцы эфирного масла из растения Hyssopus officinalis L., культивируемого в Астраханской области, и изучена зависимость его выхода от срока вегетации растения. Наибольший выход $(0,6-0,8 \%)$ эфирного масла наблюдался из соцветий иссопа. Из наземной части растения в фазе цветения эфирное масло получено с выходом 0,4\% в пересчете на воздушно-сухое сырье. Методом газожидкостной хроматографии осуществлен количественный анализ компонентов эфирного масла Hyssopus officinalis L. Из 32 обнаруженных в эфирном масле компонентов идентифицировано 27 соединений. Качественный анализ проводили путем сравнения линейных индексов удерживания и полных масс-спектров компонентов с соответствующими данными чистых соединений. Количественное содержание компонентов эфирного масла вычислялось по площадям газохроматографических пиков без использования корректирующих коэффициентов. Основными компонентами эфирного масла иссопа лекарственного являются оксигенированные монотерпены: изопинокамфон $(63,55 \%)$ и пинандиол $(9,45 \%)$. Сравнительный анализ полученных экспериментальных результатов и литературных данных по компонентному составу эфирных масел иссопа, произрастающего в других странах, показывает существенное отличие в химическом составе полученных образцов эфирного масла иссопа лекарственного. В них отсутствуют лимонен, туйоны, линалоол, а содержание $\beta$-пинена существенно меньше $(1,58 \%)$, чем в эфирном масле иссопа, выращиваемого в Польше $(6,14 \%)$ или в Индии $(18,4 \%)$.

Ключевые слова: иссоп лекарственный, пародистилляция, эфирное масло, изопинокамфон, пинандиол.

\section{Введение}

В последние годы существенно возрос интерес к эфирно-масличным растениям семейства Яснотковые, к которому принадлежит иссоп лекарственный. Это растение, вероятно, происходит из Юго-Западной Азии и Южной Европы. Это полукустарниковое растение культивируется в Восточной и Центральной Европе, во Франции, Италии, на Балканах, в Крыму и Азии [1, 2].

Эфирное масло является основным физиологически активным компонентом Hyssopus officinalis. В листьях содержание масла составляет $0,3-1,5 \%$, в соцветиях - 0,9-2,0\%, а в побегах присутствуют лишь следовые количества. Сырьем для получения эфирного масла, которое используется в пищевой, косметической и фармацевтической промышленности, служит наземная часть растения (листья, соцветия и неодревесневшие побеги). Выходы эфирного масла, полученного методом паровой дистилляции из высушенно-

Великородов Анатолий Валериевич - заведующий кафедрой органической и фармацевтической химии, доктор химических наук, профессор, e-mail: avelikorodov.chem@rambler.ru

Ковалев Вячеслав Борисович - доцент кафедры органической и фармацевтической химии, кандидат химических наук, e-mail: chemkovalevne@ mail.ru Курбанова Фарида Хазаралиевна - магистрант, e-mail: org@asu.edu.ru

Щепетова Екатерина Владимировна - доцент кафедры органической и фармацевтической химии, кандидат биологических наук, e-mail: shchepetova@yandex.ru го или свежего растительного сырья, составляют $0,15-0,3$ и $0,3-0,8 \%$ соответственно. В значительных объемах это масло получают во Франции, Италии и странах бывшей Югославии.

Масло иссопа лекарственного представляет собой жидкость светло-зеленого или светложелтого цвета с характерным камфорным запахом.

Оно обладает антибактериальным, противовирусным, противогрибковым и отхаркивающим действием [3-5]. Недавно проведенными исследо-

\footnotetext{
* Автор, с которым следует вести переписку.
} 
ваниями установлено, что эфирное масло, содержащееся в иссопе, проявляет антитромбоцитарную активность [6]. Выявлено также спазмолитическое действие эфирного масла иссопа лекарственного [7].

Выход и химический состав эфирного масла Hyssopus officinalis зависит от многих внешних факторов (климатические условия, тип почвы, происхождение растения, время заготовки сырья и др.) $[8,9]$.

Согласно литературным данным основными компонентами эфирного масла Hyssopus officinalis являются изомерные пинокамфоны, $\beta$-пинен, пинокарвон, лимонен, линалоол, $\beta$-кариофиллен, гермакрен D, туйоны, миртенол [10-12].

Хемотип иссопа, произрастающего в Турции, отличается от хемотипа иссопа, культивируемого в Польше, тем, что доминирующим компонентом эфирного масла является пинокарвон [13, 14]. Эфирное масло иссопа лекарственного из Испании характеризуется повышенным содержанием 1,8-цинеола $(52,89 \%)$ [15]. Иссоп лекарственный, культивируемый во Франции, отличается доминированием в эфирном масле линалоола (49,6\%). Особенностью этого масла является также низкое содержание монотерпеновых кетонов [16].

Изучение химического состава эфирного масла (выход 0,34\%), полученного из листьев иссопа, собранного вблизи Хандиза (бывшая Узбекская ССР) методом газовой хроматографии - хромато-массспектрометрии показало, что основными компонентами являются пинокамфон (71\%), $\beta$-пинен $(8,6 \%)$ и 1,8 цинеол $(6,4 \%)$, а лимонен и изопинакомфон отсутствовали [17].

Химический состав эфирного масла иссопа лекарственного, культивируемого в Астраханской области, ранее не изучался. Необходимость подробного изучения компонентного состава эфирного масла обусловлена тем, что в состав эфирных масел могут входить токсичные соединения, например метилэвгенол, который, согласно литературным данным [18], обладает канцерогенной активностью, а также нетерпеновые кетоны, обладающие значительным эпилептогенным действием [19].

Цель настоящей работы - исследование химического состава образцов эфирного масла Hyssopus officinalis в зависимости от типа наземной части и срока вегетации, количественное определение его основных компонентов.

\section{Экспериментальные условия}

Cblpьe Hyssopus officinalis (наземная часть) предоставлено Всероссийским научно-исследовательским институтом орошаемого бахчеводства (аптекарский огород, г. Камызяк, Россия). Сырье анализировали в свежем и сухом виде. Сухое сырье получали согласно правилам сбора и сушки лекарственных растений [20]. Сырье во избежание разрушения биологически активных веществ и для удаления излишней влаги высушивали сразу после сбора наиболее распространенным методом - воздушной сушкой, основанной на свободном доступе воздуха к растительному материалу, разложенному в затемненном месте.

Выделение эфирного масла из измельченных наземных частей (листьев, стеблей, соцветий) осуществляли методом пародистилляции при атмосферном давлении в аппарате из нержавеющей стали из воздушно-сухого сырья массой 5 кг, дистиллят отбирали в течение 4 ч. Масло сушили безводным сульфатом натрия, отделяли от осушителя декантацией. Продолжительность процесса пародистилляции установлена экспериментально на основании изучения динамики изменения выхода эфирного масла во времени. Выход эфирного масла (\%) определяли в пересчете на воздушно-сухую массу сырья.

Качественный и количественный составы образцуов эфирного масла проводили на хроматографе с масс-селективным детектором Shimadzu QP 2010. Для идентификации компонентов использовали библиотеку масс-спектров NIST 11.

Образец эфирного масла растворяли в бензоле до концентрации 0,1\% по объему. Колонка-SPB-1 30 м, диаметр 0,25 мм. Режим хроматографирования: инжектор - $180{ }^{\circ} \mathrm{C}$; детектор - $200{ }^{\circ} \mathrm{C}$; интерфейс $210{ }^{\circ} \mathrm{C}$; газ-носитель - гелий (99,99999\%), 1 мл/мин при делении потока $1: 10$; термостат - $60{ }^{\circ} \mathrm{C} 1$ мин, 2 град/мин - до $70{ }^{\circ} \mathrm{C}, 5$ град/мин - до $90{ }^{\circ} \mathrm{C}, 10$ град/мин - до $180{ }^{\circ} \mathrm{C}, 20$ град/мин - до $280{ }^{\circ} \mathrm{C}$, далее изотерма - 1 мин. Режим регистрации масс-спектров 39-350 m/z. Для определения линейных индексов эфирное масло и нормальные парафины (нонан, ундекан, тридекан и пентадекан) растворяли в бензоле. $\mu$-Парафины разбавляли до концентрации 0,007\% по объему, эфирное масло лофанта анисового - $1: 30000$ по объему. Количественное содержание компонентов эфирного масла вычислялось по площадям газохроматографических пиков без использования корректирующих коэффициентов. Качественный анализ прово- 
дили путем сравнения линейных индексов удерживания [21] и полных масс-спектров компонентов с соответствующими данными чистых соединений.

Линейные индексы удерживания рассчитывали по формуле:

$$
R I_{x}=100 n+100 k\left(t_{\mathrm{Rx}}-t_{\mathrm{Rn}} / t_{\mathrm{R}_{(\mathrm{n}+\mathrm{k})}}-t_{\mathrm{Rn}}\right),
$$

где $n$ - число атомов углерода $\mu$-парафина; $k$ - разность числа атомов углерода двух $\mu$-парафинов; $t_{\mathrm{Rx}}-$ время удерживания вещества; $t_{\mathrm{Rn}}$ - время удерживания н-парафина с $\mathrm{n}$ атомами углерода; $t_{\mathrm{R}(\mathrm{n}+\mathrm{k})}-$ время удерживания $t$-парафина с $n+k$ атомами углерода.

\section{Обсуждение результатов}

Изучение зависимости выхода эфирного масла в зависимости от сроков вегетации и вида наземной части Hyssopus officinalis показало, что наибольший выход наблюдается из соцветий (табл. 1).

В таблице 2 указаны идентифицированные соединения в эфирном масле иссопа лекарственного (наземная часть в фазе цветения, выход $0,4 \%$ ), а также их количественное содержание.

В таблице 3 приведено содержание терпенов, терпеноидов, сесквитерпенов и сесквитерпеноидов в эфирном масле иссопа лекарственного.

Таблица 1. Выход эфирного масла в различных наземных вегетативных частях и в разные сроки вегетации иссопа лекарственного

\begin{tabular}{l|c|c}
\hline $\begin{array}{l}\text { Наземная вегетативная часть } \\
\text { иссопа лекарственного }\end{array}$ & Сроки вегетации & $\underline{0,3}$ \\
\hline Листья & май - начало июня & $\underline{0,2}$ \\
Стебли & май - начало июня & 0,1 \\
Листья & середина июня - начало июля (фаза цветения) & $\underline{0,4}$ \\
Стебли & фаза цветения & $\underline{0,2}$ \\
Соцветия & фаза цветения & 0,1 \\
& & $\underline{0,8}$ \\
\hline
\end{tabular}

* В числителе и знаменателе указан выход эфирного масла соответственно из свежего и воздушно-сухого растительного материала.

Таблица 2. Количественный состав эфирного масла иссопа лекарственного

\begin{tabular}{|c|c|c|c|c|c|}
\hline $\begin{array}{c}\text { Название } \\
\text { компонента }\end{array}$ & $\begin{array}{c}\text { Индекс } \\
\text { удерживания } \\
R I \\
\end{array}$ & $\begin{array}{c}\text { Содержание, } \\
\% \text { от цельно- } \\
\text { го масла }\end{array}$ & $\begin{array}{c}\text { Название } \\
\text { компонента }\end{array}$ & $\begin{array}{c}\text { Индекс } \\
\text { удерживания } \\
R I \\
\end{array}$ & $\begin{array}{c}\text { Содержание, } \\
\% \text { от цельно- } \\
\text { го масла }\end{array}$ \\
\hline Сабинен & 951 & 0,19 & $\alpha$-боурбонен & 1372 & 0,99 \\
\hline$\beta$-пинен & 954 & 1,58 & $\beta$-кариофиллен & 1404 & 0,37 \\
\hline Мол. масса $=112 *$ & 959 & 0,22 & Аромадендрен & 1443 & 0,21 \\
\hline Эвкалиптол & 1002 & 0,34 & Лимонен-6-ол пивалат & 1452 & 0,61 \\
\hline Дигидрокарвеол & 1081 & 0.60 & $\alpha$-кариофиллен & 1457 & 0,32 \\
\hline Нопинон & 1105 & 0,48 & Гермакрен D & 1462 & 0,95 \\
\hline транс-пинакарвеол & 1118 & 1,41 & $\gamma$-элемен & 1477 & 0,18 \\
\hline Вербенол & 1124 & 0,22 & Мол. масса $=220 *$ & 1487 & 4,64 \\
\hline Мол. масса $=152 *$ & 1131 & 2,52 & $\varepsilon$-мууролен & 1494 & 0,19 \\
\hline Изопинокамфон & 1143 & 63,55 & Элеменол & 1524 & 0,71 \\
\hline Миртеналь & 1161 & 1,58 & Спатуленол & 1549 & 1,08 \\
\hline$\alpha$-терпинеол & 1166 & 0,21 & Кариофиллен оксид & 1553 & 1,42 \\
\hline Миртенол & 1171 & 1,39 & Мол. масса $=182 *$ & 1577 & 2,31 \\
\hline транс-2-пиналол & 1181 & 0,72 & $\tau$-кадинол & 1614 & 0,18 \\
\hline Пинандиол & 1212 & 9,45 & Кубенол & 1636 & 0,33 \\
\hline Миртаналь & 1292 & 0,86 & Мол. масса $=268 *$ & 1818 & 0,18 \\
\hline
\end{tabular}

*неидентифицированное соединение. 
Таблица 3. Содержание основных компонентов эфирного масла

\begin{tabular}{|c|c|c|}
\hline № ח/п & Компоненты эфирного масла & Содержание, \% \\
\hline 1 & Монотерпеновые углеводороды ( $\beta$-пинен, сабинен) & 1,77 \\
\hline 2 & $\begin{array}{l}\text { Сесквитерпеновые углеводороды ( } \beta \text {-кариофиллен, гермакрен D, аромадендрен, } \\
\alpha \text {-боуробонен, } \varepsilon \text {-мууролен, } \gamma \text {-элемен, } \alpha \text {-кариофиллен) }\end{array}$ & 3,21 \\
\hline 3 & $\begin{array}{l}\text { Оксигенированные монотерпены (изопинокамфон, нопинон, } \alpha \text {-терпинеол, транс- } \\
\text { пинокарвеол, мертаналь, пинандиол, мертенол, лимонен-6-ол пивалат, транс-2-пиналол, } \\
\text { вербенол, дигидрокарвеол, эквалиптол, миртеналь) }\end{array}$ & 81,42 \\
\hline 4 & $\begin{array}{l}\text { Оксигенированные сесквитерпены (кубенол, } \tau \text {-кадинол, кариофиллен оксид, спатуленол, } \\
\text { элемол) }\end{array}$ & 3,72 \\
\hline 5 & Неидентифицированные соединения & 9,87 \\
\hline \multicolumn{2}{|r|}{ Итого } & 100 \\
\hline
\end{tabular}

Как следует из приведенных данных, основными компонентами эфирного масла иссопа лекарственного являются оксигенированные монотерпены: изопинокамфон $(63,55 \%)$ и пинандиол $(9,45 \%)$.

Сравнительный анализ полученных экспериментальных результатов и литературных данных по компонентному составу эфирных масел иссопа, произрастающего в других странах (Сербии, Польше) [2, 13], показывает существенное отличие в химическом составе эфирного масла иссопа лекарственного, культивируемого в Астраханской области. Так, содержание $\beta$-пинена в эфирном масле существенно меньше $(1,58 \%)$, чем в эфирном масле иссопа, выращиваемого в Польше $(6,14 \%)$ или в Индии $(18,4 \%)$.

\section{Заключение}

Таким образом, проведенные исследования позволили выявить качественный и количественный химический состав эфирного масла растения Hyssopus officinalis L., культивируемого в Астраханской области. Иссоп лекарственный может служить сырьем для получения эфирного масла, основными компонентами которого являются изопинокамфон и пинандиол.

\section{Список литературы}

1. Hoppe H.A. Drogenkunde. Berlin ; New York, 1975.

2. Baj T., Kowalski R., Światek Ł., Modzelewska M., Wolski T. Chemical composition and antioxidant activity of the essentials oil of hyssop (Hyssopus officinalis L. ssp officinalis) // Ann. Univ. Mariae Curie-Skłodowska. 2010. Vol. 23, N3. Sect. DDD. Pp. 55-62.

3. Fraternale D., Ricci D., Epifano F., Curini M. Composition and antifungal activity of two essential oils of hyssop (Hyssopus officinalis L.) // J. Essent Oil Res. 2004. Vol. 16, N6. Pp. 617-622.

4. Garg S.N., Naqvi A.A., Singh A., Ram G., Kumar S. Composition of essential oil from an annual crop of $H$. officinalis grown in Indian Plains // Flav. Fragr. J. 1999. Vol. 14, N3. Pp. 170-172.

5. Renzini G., Scazzocchio F., Lu M., Mazzanti G., Salvatore G. Antibacterial and Cytotoxic Activity of Hyssopus officinalis L. oil // J. Essent. Oil Res. 1999. Vol. 11, N5. Pp. 649-654.

6. Tognolini M., Barocelli E., Ballabeni V., Bruni R., Bianchi A., Chiavarini M., Impicciatore M. Comparative screening of plant essential oils: Phenylpropanoid moiety as basic core for antiplatelet activity // Life Sci. 2006. Vol. 78. Pp. 1419-1432.

7. Lu M., Battinelli L., Daniele C., Melchioni C., Salvatore G., Mazzanti G. Muscle relaxing activity of Hyssopus officinalis essential oil on isolated intestinal preparations // Planta Med. 2002. Vol. 68, N3. Pp. 213-216.

8. Wolski T., Baj T., Kwiatkowski S. Hyzop lekarski (Hyssopus officinalisL.) zapomniana roślina lecznicza, przyprawowa oraz miododajna // Ann. Univ. Mariae Curie-Skłodowska. 2006. Vol. 41, N1. Sect. DD. Pp. 1-10.

9. Wolski T., Baj T. Hyzop lekarski (Hyssopus officinalis L.) aromatyczna roślina lecznicza // Aromaterapia. 2006. Vol. 4, N46. Pp. 10-18.

10. Gorunović M., Bogavac P., Chulchat J., Chabardi J. Essential oil of Hyssopus officinalis L. Lamiaceae of Montenegro Origin // J. Essent. Oil Res. 1995. Vol. 7. Pp. 39-43.

11. Mazzanti G., Battinelli L., Salvatore G. Antimicrobial properties of the linalool-rich essential oil of Hyssopus officinalis L. var decumbens (Lamiaceae) // Flavour Fragr. J. 1998. Vol. 13. Pp. 289-294.

12. Özer H., Şahin F., Kiliç H., Güllüce M. Essential oil composition of Hyssopus officinalis L. subsp. angustifolius (Bieb.) Arcangeli from Turkey // Flavour Fragr. J. 2005. Vol. 20, N1. Pp. 42-44.

13. Mitić V., Đorđević S. Essential oil composition of Hyssopus oficinalis L. cultivated in Serbia // Facta univ. Ser. Phys., Chem. and Techn. 2000. Vol. 2, N2. Pp. 105-108.

14. Joulain D., König W.A. The Atlas of Spectral Data of Sesquiterpene Hydrocarbons. E.B.-Verlag, Hamburg, 1998.

15. Vallejo M., Herraiz J., Perez-Alonso M., Velasco-Negueruela A. Volatile oil of Hyssopus officinalis L. from Spain // J. Essent. Oil Res. 1995. Vol. 7. Pp. 567-568. 
16. Salvatore G., D'Andrea A., Nicoletti M. A pinocamphone poor oil of Hyssopus officinalis L. var. decumbens from France (Banon) // J. Essential Oil Res. 1998. Vol. 10. Pp. 563-567.

17. Dzhumaev Kh.K., Zenkevich I.G., Tkachenko K.G., Tsibul'skaya I.A. Essential oil of the leaves of Hyssopus seravschanicus from South Uzbekistan // Chem. Nat. Comp. 1990. Vol. 26, N1. Pp. 101-102.

18. De Vincenzi M., Silano M., Stacchini P., Scazzocchio B. Constituents of aromatic plants: I. Methyleugenol // Fitoterapia. 2000. Vol. 71. N2. Pp. 216-221.

19. Burfield T. Safety of essential oils // Int. J. Aromather. 2000. Vol. 10, N1-2. Pp. 16-29.

20. Правила сбора и сушки лекарственных растений. М., 1985. 321 с.

21. Ткачев А.В. Исследование летучих веществ растений. Новосибирск, 2008. 969 с.

Поступило в редакичию 14 мая 2015 2.

После переработки 26 июня 2015 г. 
Velikorodov A.V., Kovalev V.B., Kurbanova, F.Kh. Shchepetova E.V. CHEMICAL COMPOSITION OF ESSENTIAL OIL OF HYSSOPUS OFFICINALIS L., CULTIVATED IN THE ASTRAKHAN REGION

\section{Astrakhan State University, Shaumyan sq., 1, Astrakhan,414000 (Russia),e-mail: avelikorodov@mail.ru}

By hydro distillation method were obtained samples of essential oils from Hyssopus officinalis L., cultivated in the Astrakhan region and the dependence of its yields from the plant vegetation period was studied. The highest yield of essential oil from flowers $(0,6-0,8 \%)$ was observed. From the ground plant parts in the flowering stage essential oil was obtained in $0,4 \%$ yield of based on air-dry feed. Quantitative analysis of the components of essential oil of Hyssopus officinalis L. was performed by GLC method. From the 32 founded components in the essential oil were identified 27 compounds. Qualitative analysis was performed by comparing retention indices and linear full mass spectra data components with corresponding pure compounds. Quantification of components of essential oil was calculated from the gas chromatographic peak areas without correction factors. The main components of hyssop essential oil were oxygenated monoterpenes: isopinocamphone $(63,55 \%)$ and pinanediol $(9,45 \%)$. Comparative analysis of the experimental results and the literature data on the component composition of essential oils of hyssop growing in other countries shows a significant difference in the chemical composition of the obtained samples of Hyssop officinalis L. essential oil. They lack limonene, thujones, linalool, and $\beta$-pinene content is significantly less $(1,58 \%)$ than in the essential oil of hyssop grown in Poland (6,14\%) and India (18,4\%).

Keywords: Hyssopus officinalis L., hydro distillation, essential oil, chemical composition, gas liquid chromatography, isopinocamphone, pinanediol.

\section{References}

1. Hoppe H.A. Drogenkunde. Berlin ; New York, 1975.

2. Baj T., Kowalski R., Światek Ł., Modzelewska M., Wolski T. Ann. Univ. Mariae Curie-Skłodowska, 2010, vol. 23, no. 3, sect. DDD, pp. 55-62.

3. Fraternale D., Ricci D., Epifano F., Curini M. J. Essent Oil Res., 2004, vol. 16, no. 6, pp. 617-622.

4. Garg S.N., Naqvi A.A., Singh A., Ram G., Kumar S. Flav. Fragr. J., 1999, vol. 14, no. 3, pp. 170-172.

5. Renzini G., Scazzocchio F., Lu M., Mazzanti G., Salvatore G. J. Essent. Oil Res., 1999, vol. 11, no. 5, pp. 649-654.

6. Tognolini M., Barocelli E., Ballabeni V., Bruni R., Bianchi A., Chiavarini M., Impicciatore M. Life Sci., 2006, vol. 78, pp. 1419-1432.

7. Lu M., Battinelli L., Daniele C., Melchioni C., Salvatore G., Mazzanti G. Planta Med., 2002, vol. 68, no. 3, pp. $213-216$.

8. Wolski T., Baj T., Kwiatkowski S. Ann. Univ. Mariae Curie-Skłodowska, 2006, vol. 41, no. 1, sect. DD, pp. 1-10.

9. Wolski T., Baj T. Aromaterapia, 2006, vol. 4, no. 46, pp. 10-18.

10. Gorunović M., Bogavac P., Chulchat J., Chabardi J. J. Essent. Oil Res., 1995, vol. 7, pp. 39-43.

11. Mazzanti G., Battinelli L., Salvatore G. Flavour Fragr. J., 1998, vol. 13, pp. 289-294.

12. Özer H., Şahin F., Kiliç H., Güllüce M. Flavour Fragr. J., 2005, vol. 20, no. 1, pp. $42-44$.

13. Mitić V., Đorđević S. Facta univ. Ser. Phys., Chem. and Techn., 2000, vol. 2, no. 2, pp. 105-108.

14. Joulain D., König W.A. The Atlas of Spectral Data of Sesquiterpene Hydrocarbons. E.B.-Verlag, Hamburg, 1998.

15. Vallejo M., Herraiz J., Perez-Alonso M., Velasco-Negueruela A. J. Essent. Oil Res., 1995, vol. 7, pp. 567-568.

16. Salvatore G., D'Andrea A., Nicoletti M. J. Essential Oil Res., 1998, vol. 10, pp. 563-567.

17. Dzhumaev Kh.K., Zenkevich I.G., Tkachenko K.G., Tsibul'skaya I.A. Chem. Nat. Comp., 1990, vol. 26, no. 1, pp. 101-102.

18. De Vincenzi M., Silano M., Stacchini P., Scazzocchio B. Fitoterapia, 2000, vol. 71, no. 2, pp. 216-221.

19. Burfield T. Int. J. Aromather., 2000, vol. 10, no. 1-2, pp. 16-29.

20. Pravila sbora i sushki lekarstvennykh rastenii. [The rules for collecting and drying herbs]. Moscow, 1985, $321 \mathrm{p}$. (in Russ.).

21. Tkachev A.V. Issledovanie letuchikh veshchestv rastenii. [The study of plant volatiles]. Novosibirsk, 2008.969 p. (in Russ.).

Received May 14, 2015

Revised June 26, 2015

\footnotetext{
* Corresponding author.
} 